\title{
Larvicidal Activity of the Mixture of Cashew Nut Shell Liquid (CNSL) and Aqueous Extract of Sapindus rarak DC against Larvae of Culex quinquefasciatus
}

\author{
Rahmi Safarina Fauziah $^{1}$, Sudarsono ${ }^{{ }^{*}}$ and Budi Mulyaningsih $^{\mathbf{2}}$ \\ ${ }^{1}$ Pharmaceutical Biology Department, Faculty of Pharmacy; ${ }^{2}$ Parasitology Laboratory, Faculty of Medicine, UGM, Indonesia \\ Author correspondency*: \\ sudarsono@ugm.ac.id
}

\begin{abstract}
The aim of this study was to evaluate the larvicidal activity of Cashew Nut Shell Liquid (CNSL) against the Culex quinque fasciatus in larval stage. The CNSL was diluted in water by addition of aqueous extract of Sapindus rarak DC to increase its solubility. Larvae were exposed to varying concentrations of that mixture. The larvae mortality was observed after $24 \mathrm{~h}$ exposure. $\mathrm{LC}_{50}$ and $\mathrm{LC}_{90}$ value by extrapolation were $20,52 \mathrm{ppm}$ and 55,41 ppm respectively. CNSL were specified by characterizing its physico-chemical properties and anacardic acid as marker compound by High Performance Chromatography (HPLC). The results were the mixture of Cashew Nut Shell Liquid (CNSL) and Aquous extract of Sapindus rarak DC had larvicidal activity against Cx. Quinque-fasciatus and further investigations were needed to identify the fatty acid derivative as active compound of CNSL which responsible for larvicidal activity.
\end{abstract}

Keywords: larvicidal, larvae, Culex quinquefasciatus, Cashew Nut Shell Liquid, Sapindus rarak

\section{Introduction}

Culex quinquefasciatus is the most common mosquito species found in Indonesia. There are the main cause of the mosquito bites in the evenings and night. The main factor supporting this species is probably due to poor sanitation caused by human migration to urban areas. Interest in the control of Cx.quinquefasciatus lies in the fact that it acts as a vector of filarial disease as a serious public health problem in Indonesia and many tropical developing countries. Filariasis is an endemic, disabling, and disfiguring disease. The filarial worm, Wuchereria bancrofti responsible for human filariasis is carried by Cx.quinquefasciatus which is a tropical pest and probably the most abundant and ubiquitous house mosquito in towns and cities, in the tropical countries.

One of the strategies of WHO in combating tropical disease is to destroy their vectors or intermediate hosts. Since no effective vaccine is available for filariasis, the only effective approach of minimizing the incidence of this disease is to eradicate and control mosquito vectors mainly by application of organic insecticides to larval habitats. Control of mosquito at this stage is efficient because during the immature stages, mosquitoes are immobile.

The use of natural products for controlling of insect pests offers an economically viable and eco-friendly approach, besides being harmless to beneficial insects when adopted on a larger scale. Chemical pesticides have been used for several decades in controlling pests and vectors of various human diseases as they have a quick knock down effect. However, their indiscriminate use resulted in several problems such as resistance and resurgence of pests, elimination of natural enemies, toxic residues in food, water, air, and soil which affect human health and disrupt the ecosystem, leading to the threat that their continued use may further harm the environ-ment.

Anacardium occidentale L. (Anacardiaceae), a fruit tree grown widely in tropical and sub-tropical areas is cultivated in Indonesia for its cashew nuts. Tyman \& Morris in 1989 described the composition of CNSL which found between the seed coat (pericarp) and the nuts. It is not a triglyceride and contains a high portion of phenolic compound, mainly are anacardic acid, cardol, and cardanol. Recently, Lomonaco and Oliveira noted insecticidal action of CNSL on larvae of Aedes aegypti (Diptera: Culicidae). The three CNSL compo-nents demonstrated good larvicidal activity against Ae. aegypti.

Despite the potential to be developed as larvicides, phenolic compounds in the CNSL was toxic because it induced dermatitis. In addition, application of CNSL as larvicides in the medium of water is also cumbersome, so it is necessary to add other materials intended to dilute it. In this study, aqueous extract of Sapindus rarak DC was added to increase the solubility of CNSL in water.

\section{Materials and Methods}

\section{Plant materials}

Cashew nuts were obtained from cashew trees (A.occidentale) at Wonogiri, Central Java, Indonesia. The fruits of Sapindus rarak DC were collected from the areas of "Perhutani" located in Situbondo, East Java, Indonesia. The plant material was identified by Mr.Joko Santosa and Voucher specimen was deposit at Deprtment of Pharmaceutical Biology Faculty of Pharmacy, UGM. 


\section{Oil Extraction of CNSL}

The dried cashew nut shell $(1,3 \mathrm{~kg})$ were pressed by hydraulic pressor to obtain Cashew Nut Shell Liquid (CNSL).

\section{Preparation of aquous extracts of S.rarak}

The dried pericarp from S.rarak $(10 \mathrm{~g})$ were cut into small pieces then extracted with $1000 \mathrm{~mL}$ of distilled water by reflux process at $50^{\circ} \mathrm{C}$ for 30 minutes. The concentration of aqueous extract of S.rarak fruits was $1 \% \mathrm{~b} / \mathrm{v}$.

\section{Reagents}

N-Toluene (E.Merck), Ethyl acetate (E.Merck), Acetic acid glacial (E.Merck), Chloroform (Brataco), Methanol (Brataco). Iodium P, Anisaldehyde-sulphuric acid LP, Vanilin-sulphuric acid LP, ethanol 96\% (Brataco), nhexane (Brataco), Hydrochloric acid (E.Merck). All other chemicals used were analytical grade.

\section{Larvicidal assay}

The activity of the test materials were evaluated by the World Health Organization recommended guidelines.

The larvicidal assay consisted of two steps. First was the orientation to determine a certain concentration of aqueous extract of $S$. rarak DC. (It was the biggest concentration which is not found any died larvae). The chosen concentration then was used for making the mixture of CNSL and aquous extract of S. rarak DC. The next step was dissolving CNSL in various amount so that it was obtained 6 concentration series of the mixture for used in the testing, which were $0 ; 8 ; 8,56 ; 9,16 ; 9,8$; and $10,49 \mathrm{ppm}$.

\section{Characterization of CNSL's physico-chemical properties}

Physico-chemical properties of cashew nut shell oil was characterized through the iodine number, esther number, and acid number. Those properties were characterized by Pusat Antar Universitas (PAU) - UGM.

\section{HPLC analysis of CNSL constituents}

The identity of anacardic acid was confirmed by HPLC. The analysis was carried out using a Shimadzu SPD10VP chromatograph, UV-VIS detector, which utilized a Lichochart RD-C18 analytical column. The mobile phase consisted of methanol-acetic acid $4 \%(9: 1 \mathrm{v} / \mathrm{v})$, which was run in the isocratic mode phase $(1 \mathrm{~mL} / \mathrm{min})$ at a UV wavelength of $280 \mathrm{~nm}$.

\section{Determination of Foaming Index of S.rarak source}

$5 \mathrm{~g}$ of dried S.rarak fruits was dissolved in distilled water and then heated $50^{\circ} \mathrm{C}$ for 5 minutes. $10 \mathrm{~mL}$ filtrate was used for foaming test. Saponin test was performed by agitation in $10 \mathrm{~mL}$ of the filtrate in a closed tube for 10 minutes. Incidence foam up interval of 10 minutes (stable foam) showed a saponin.

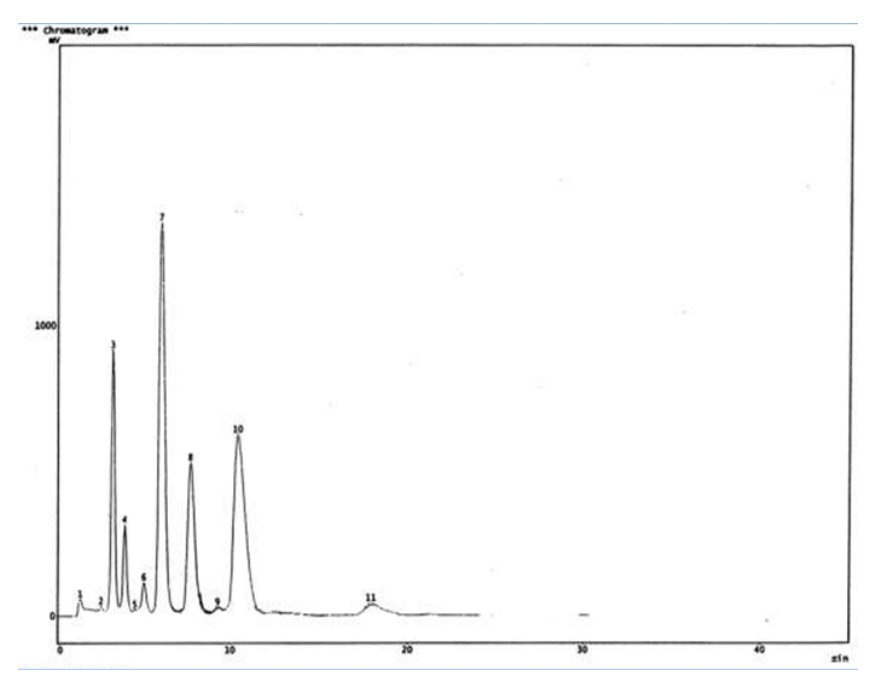

Figure.1. Chromatogram of CSNL.

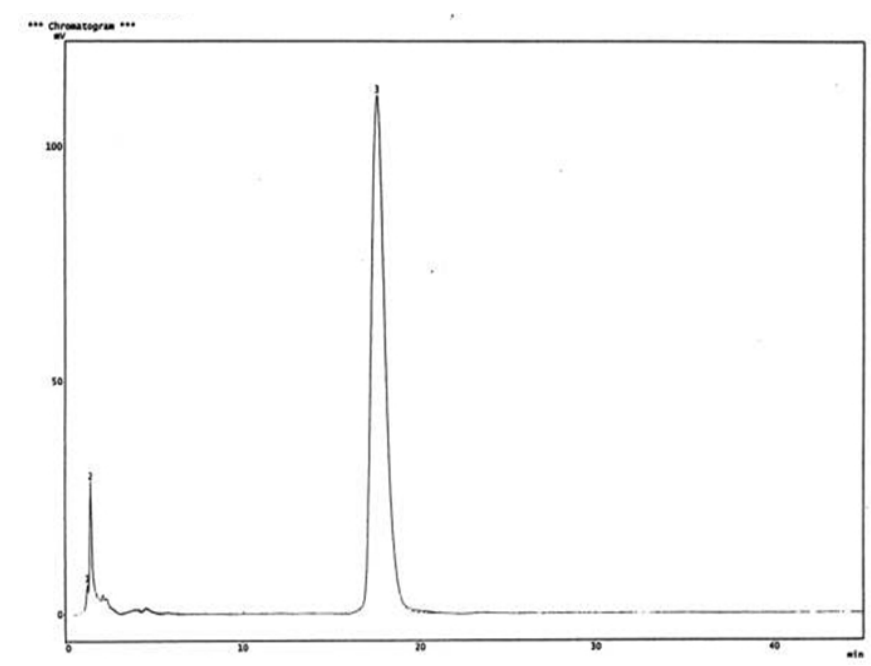

Figure.2. Chromatogram of Anacardic acid.

\section{Results and Discussion}

One of the marker constituent of CNSL, anacardic acid, was detected in the sample of CNSL in relative concentration of $2,58 \%$. The HPLC chromatograms were shown in fig. 1 and fig. 2 .

Due to its bad solubility, CNSL was diluted in water with S.rarak's pericarp extract as a co-solvent, in concentration which was determined by the orientation test. Concentration of $400 \mathrm{ppm}$ was selected as the optimum concentration to dillute CNSL in water but it had no effect to cause larval mortality. The mixture of CNSL and S.rarak extract used in this study was visually clear. There were also not detected visible oil particles or any breaking phase. 
Table 1. Physico-chemical properties of CNSL used in this study.

\begin{tabular}{ll}
\hline Physico-chemical properties of CNSL & Value \\
\hline Iodium number (g iod/10 g CNSL) & 6,3 \\
Acid number (mg NaOH/g CNSL) & 104,1 \\
Saponification number & 127,1 \\
Esther number & 45,9 \\
Density $(\mathrm{g} / \mathrm{mL})$ & 0,8232 \\
\hline
\end{tabular}

It had no published data available of effect of CNSL on immature stages of Culex mosquitoes. Effect of different concentrations of CNSL solution on aquatic stages of Cx.quinquefasciatus larvae in the laboratory conditions was shown in Table 2.

There was significant decreasing mortality percentage of the larvae by increasing CNSL concentration (table 2). As shown in that Table, the biggest death rate was noticed in exposure to $10,49 \mathrm{ppm}$ concentration.

LC line equation obtained from probit analysis was y $=3.01 \mathrm{x}+1.05$, so that the calculation could be known that $\mathrm{LC}_{50}$ and $\mathrm{LC}_{90}$ value were $20.52 \mathrm{ppm}$ and $55.41 \mathrm{ppm}$, respectively. This value was the result of extrapolation and therefore could not guarantee that these results show the actual value of $\mathrm{LC}_{50}$ and $\mathrm{LC}_{90}$.

Essential oils or plant extracts with $\mathrm{LC}_{50}$ values below $100 \mathrm{ppm}$ can be considered potentially have larvicidal activity. Our present observation reveals that Cx.quenquefasciatus larvae were susceptible to $8 \mathrm{ppm}$ to 10,49 ppm CNSL.

In Indonesia, population of Cx.quin-quefasciatus is controlled by using of organophosphate insecticides, such as temephos and Malathion. Temephos, which is also known as "Abate" has been used in areas of water where the Cx.quinquefasciatus mosquito breeds in order to reduce the population of this disease-carrying insect. Resistance to temephos by Cx.quinquefasciatus has been reported in Brazilian and Malaysia. Temephos was very lethal toward Cx.quinquefasciatus larvae with a $\mathrm{LC}_{50}=0,00088 \mathrm{ppm}$. CNSL consti-tuents were less active than temephos, but could be important models for the further development of new larvicides. It is necessary to investigate the effectiveness of these mixture compounds in a field setting and the toxicity toward other organisms, for example by doing brine shrimp lethality test.

\section{Conclusions}

In the present work the mixture of CNSL in aquaeous extract of S.rarak DC could be used as larvicide against.

Cx.quinquefasciatus. Given the continual search for renewable and biodegradable sources of new medicinal products, CNSL from cashew nut processing industries in Indonesian agribusiness represents an opportunity to increase the value of this by-product by developing green larvicidal compounds to be used in filariasis control, which is cheap, non-toxic, and biodegradable.

Table 2. Larvicidal activity of CNSL and S.rarak extract mixture against Cx.quinque fasciatus larvae.

\begin{tabular}{cccccc}
\hline $\begin{array}{c}\text { CNSL } \\
(\mathbf{p p m})\end{array}$ & $\begin{array}{c}\text { Number of larva died } \\
\text { (3 replications) }\end{array}$ & & $\begin{array}{c}\text { Total } \\
\text { larvae }\end{array}$ & $\begin{array}{c}\text { Mortality } \\
(\%)\end{array}$ \\
\cline { 2 - 4 } & $\mathbf{1}$ & $\mathbf{2}$ & $\mathbf{3}$ & & \\
\hline 0 & 1 & 1 & 0 & 75 & 2.67 \\
8 & 2 & 4 & 4 & 75 & 13.33 \\
8,56 & 5 & 3 & 3 & 75 & 14.67 \\
9,16 & 7 & 3 & 3 & 75 & 17.33 \\
9,8 & 6 & 9 & 0 & 75 & 20 \\
10,49 & 8 & 5 & 3 & 75 & 21.33 \\
\hline
\end{tabular}

\section{Acknowledgement}

I would like to thanks to Faculty of Pharmacy and Parasitology Laboratory UGM for the possibility for doing experiment.

\section{References}

Cheng, S.S., Chang, H.T., Chang, S.T., Tsai, K.H. \& Chen, W.J., 2003, Bioactivity of selected plant essential oils against the yellow fever mosquito Aedes aegypti larvae, Bioresearch Technology, 89, 99-102.

Devine GJ, Furlong MJ. Insecticide use: Contexts and ecological successions. Agric Hum Values 2007; 24: 281-306.

Evans, F.J. \& Schmidt, R.J., 1980, Plants and Plant Products That Induce Contact Dermatitis, Planta Medica, 38, 289-316.

Lima, J.B.P., Da-Cunha, M.P., Silva Júnior, R.C., Galardo, A.K.R., Soares, S.S., Braga, M.A., Ramos, R.P., Valle, D., 2003. Resistance of Aedes aegypti to organophosphates in several municipalities in the State of Rio de Janeiro and Espírito Santo, Brazil. Am. J. Trop. Med. Hyg. 68, 329-333.

Lomonaco, D., Gilvandete, M.P.S., Yana, S.F., Angela, M.C.A., Selma, E.M., Mele, G., \& Vasapollo, G., 2009, Study of technical CNSL and its main components as new green larvicides, Green Chemistry, 1, 31-33.

Oliveira, M.S.C., de Morais, S.M., Magalhaes, D.V., Batista, W.P., Vieira, G.P., \& Craveiro, A.A., 2011, Antioxidant, larvicidal, and antiacetylcholinesterase activities of cashew nut shell liquid constituents, Acta Tropica, 117, 165-170.

Samuel T, Jayakumar M, William SJ. 2007, Culex mosquito: An overview. In: William SJ. Defeating the public enemy, the mosquito: A real challenge. Loyola Publications: Chennai, p. 95-116.

Shian, L.C., 2007, The Effect of Sublethal Concentration of Abate on Aedes aegypti (Linnaeus) and Culex quinquefasciatus (Say), Tesis, Universiti Sains Malaysia, Subang Jaya.

Tennyson, S., Ravindran, J.K. \& Arivoli, S., 2012, Screening of twenty five plant extracts for larvicidal activity against Culex quinquefasciatus Say (Diptera: Culicidae), Asian Pacific Journal of Tropical Biomedicine, S1130-S1134.

Tyman JHP, Morris LJ. Composition of cashew nut shell liquid. $J$ Chromatography 1989; 27: 287-8.

World Health Organization (WHO), 2005, Guidelines for Laboratory and Field Testing of Mosquito Larvicides, Geneva. 
